\title{
O USO DE TECNOLOGIAS DIGITAIS NO PROCESSO DE APRENDIZAGEM NO ENSINO REMOTO: UMA REFLEXÃO NECESSÁRIA
}

THE USE OF DIGITAL TECHNOLOGIES IN THE LEARNING PROCESS: A NECESSARY REFLECTION

EL USO DE TECNOLOGÍAS DIGITALES EN EL PROCESO DE APRENDIZAJE: UNA REFLEXIÓN NECESARIA

\section{Mônica Vieira da Silva \\ (iD) 9 \\ Mestranda em Ensino \\ (IFMT/Kroton) \\ Secretária na Escola Estadual \\ Conquista D'Oeste \\ monicaconq@hotmail.com}

\section{Edione Teixeira de \\ Carvalho \\ (iD) 9}

Doutora em Ciências Pedagógicas

(UFBA)

Professora do Mestrado em Ensino do IFMT parceria com o Grupo

Kroton

edione.carvalho@svc.ifmt.edu.br

\begin{abstract}
Resumo
Com uma sociedade cada vez mais tecnológica, a educação precisa estar atenta e acompanhar essas mudanças. Refletir sobre os impactos que a inserção tecnológica causa no contexto educacional é o objetivo desse trabalho. Através de uma pesquisa bibliográfica, de natureza aplicada, com abordagem qualitativa e exploratória, o estudo de caso utilizou um questionário aberto e observações das práticas docentes como instrumentos de coleta de dados. A pesquisa realizada com 14 professores da Escola Estadual Conquista D'Oeste evidenciou o porquê de os professores resistirem tanto a essa nova realidade e como a formação continuada pode ajudar a quebrar essa resistência. Também revela a importância da inserção das Tecnologias de Informação na educação, observando as necessidades dos educandos, favorecendo a integração dos estudantes no processo de construção do conhecimento, uma vez que eles já crescem informatizados, o que torna imprescindível para a educação a qualificação de seus profissionais.
\end{abstract}

Palavras-chave: Tecnologias da Educação. Aprendizagem. Formação continuada.

Recebido em: 10 de agosto de 2021.

Aprovado em: 2 de novembro de 2021.

Como citar esse artigo (ABNT):

SILVA, Mônica Vieira da; CARVALHO, Edione Teixeira de. $\mathrm{O}$ uso de tecnologias digitais no processo de aprendizagem no ensino remoto: Uma reflexão necessária. Revista Prática

Docente, v. 6, n. 3, e095, 2021.

http://doi.org/10.23926/RPD.2021.v6.n3.e095.id1294 


\begin{abstract}
With an increasingly technological society, education needs to be aware of and keep up with these changes. Reflecting on the impacts that technological insertion causes in the educational context is the objective of this work. Through a bibliographical research, of an applied nature, with a qualitative and exploratory approach, the case study used an open questionnaire and observations of teaching practices as data collection instruments. The survey carried out with 14 teachers from the Conquista D'Oeste State School showed why teachers are so resistant to this new reality and how continuing education can help to break this resistance. It also reveals the importance of inserting Information Technologies in education, observing the needs of students, favoring the integration of students in the knowledge construction process, since they already grow up computerized, which makes the qualification of their students essential for education. professionals.
\end{abstract}

Keywords: Education Technologies. Learning. Continuing training.

\title{
Resumen
}

Con una sociedad cada vez más tecnológica, la educación debe ser consciente y mantenerse al día con estos cambios. Reflexionar sobre los impactos que provoca la inserción tecnológica en el contexto educativo es el objetivo de este trabajo. A través de una investigación bibliográfica, de carácter aplicado, con enfoque cualitativo y exploratorio, el estudio de caso utilizó un cuestionario abierto y observaciones de prácticas docentes como instrumentos de recolección de datos. La encuesta realizada a 14 docentes de la Escuela Estatal Conquista D'Oeste mostró por qué los docentes se resisten tanto a esta nueva realidad y cómo la educación continua puede ayudar a romper esta resistencia. También revela la importancia de insertar las Tecnologías de la Información en la educación, observando las necesidades de los estudiantes, favoreciendo la integración de los estudiantes en el proceso de construcción del conocimiento, dado que ya crecen informatizados, lo que hace que la calificación de sus estudiantes sea fundamental para los profesionales de la educación.

Palabras clave: Tecnologías de la educación. Aprendiendo. Formación continua. 


\section{INTRODUÇÃo}

O cenário educacional que estamos vivendo desde 2020 com a pandemia da Covid-19, sem dúvida contribuiu para a formação de uma "Sociedade Tecnológica". Este trabalho foi desenvolvido no sentido de que as novas tecnologias sejam vistas como alternativas que podem auxiliar o processo de educação, como dinamizadora do processo de ensino e como instigadoras para a melhoria da aprendizagem.

Refletir sobre o uso das novas tecnologias para a melhoria do processo de ensino e de aprendizagem se tornou uma temática dentro de todas as unidades de ensino, uma vez que a simples utilização de um ou outro equipamento tecnológico não pressupõe um trabalho educativo pedagógico. A escola tem um novo desafio pela frente, o de utilizar essas novas possibilidades tecnológicas como estratégias de aprendizagem, fazendo com que elas tornem as aulas mais dinâmicas e criativas.

Diante da importância da incorporação dessas tecnologias educacionais, é essencial que a escola busque promover a formação continuada, além de proporcionar ambientes colaborativos de aprendizagem para que os alunos sejam capazes de observar que essas ferramentas podem, além de proporcionar momentos de lazer e entretenimento, contribuir para um processo de aprendizagem de forma autônoma e prazerosa.

O objetivo do artigo é fazer uma reflexão sobre os impactos que a inserção tecnológica causa no contexto educacional. Pois além de auxiliar no processo de aprendizagem, essas tecnologias ajudam a promover maior articulação entre a área administrativa, pedagógica, familiar e toda a comunidade escolar.

A pesquisa bibliográfica, de natureza aplicada, teve uma abordagem qualitativa, classificada como exploratória e de estudo de caso, comprova que a resistência a essas mudanças tem provocado grande preocupação dentro do cenário educacional e revela a importância da inserção das Tecnologias de Informação na educação, observando as necessidades dos educandos, favorecendo a integração dos estudantes no processo de construção do conhecimento, uma vez que eles já crescem informatizados, o que torna imprescindível para a educação, a qualificação de seus profissionais. Diante dessa problemática, urge a necessidade de refletir sobre o papel das novas tecnologias na educação e os desafios enfrentados pelos professores e gestores para adaptar essas novas metodologias no processo de aprendizagem. 


\section{REFERENCIAL TEÓRICO}

As Tecnologias da Informação ou Comunicação são o resultado da fusão de três vertentes técnicas: a informática, as telecomunicações e as mídias eletrônicas (ARAUJO; VILAÇA, 2016). Elas diminuíram e estreitaram os conceitos de espaço e distância, como as redes eletrônicas e o telefone celular, que nos proporcionam ter em nossas mãos o que antes estava a quilômetros de distância, isso foi comprovado no ano de 2020 e 2021, quando todo o mundo precisou fazer isolamento social devido à pandemia da Covid -19.

$\mathrm{Na}$ "Sociedade Tecnológica", esse é o cenário atual que estamos vivendo, em que a maioria tem acesso a várias tecnologias, mas, no entanto, essa mesma maioria também não sabe usufruir de todos esses recursos que estão ao seu alcance, principalmente quando se trata de educação (ARAUJO; VILAÇA, 2016). Todo esse contexto vivenciado durante a pandemia, também nos fez refletir sobre as diferenças sociais e como ela afeta a educação on-line.

Moram (2007) afirma que as escolas, na maioria das vezes, não conseguem proporcionar toda a informação relevante e necessária aos educandos, desta forma, o mais importante é formar os aprendizes para terem acesso a ela na medida de suas necessidades, ou seja, preparálos para continuarem o processo de aprendizagem de forma autônoma. Para Libâneo (2007, p. 309), "o grande objetivo das escolas é a aprendizagem dos alunos, e a organização escolar necessária é a que leva a melhorar a qualidade dessa aprendizagem". Porém nem todos têm a mesma oportunidade de aprendizagem em casa, as diferenças sociais são gritantes.

Quando falamos em tecnologias educacionais, nos referimos ao uso dos recursos tecnológicos como ferramenta para melhorar o processo de aprendizagem. Diante disso, é fato de que o conhecimento e o domínio do saber em relação a essas ferramentas são de responsabilidade do professor, mas a gestão tem um papel fundamental, o de fomentar a utilização das mesmas dentro do ambiente escolar.

O Gestor Escolar tem grande importância na inserção das novas tecnologias dentro do ambiente escolar, cabe a ele elaborar um planejamento e a iniciativa de criar espaços de reflexão e experimentação. De acordo com Almeida (2004, p. 2),

\footnotetext{
o envolvimento dos gestores escolares na articulação dos diferentes segmentos da comunidade escolar, na liderança do processo de inserção das TIC na escola em seus âmbitos administrativo e pedagógico e, ainda, na criação de condições para a formação continuada e em serviço dos seus profissionais, pode contribuir e significativamente para os processos de transformação da escola em um espaço articulador e produtor de conhecimentos compartilhados.
} 
Cabe à gestão oportunizar a oferta de cursos de formação continuada e acesso às tecnologias no ambiente escolar. O gestor deve buscar junto aos órgãos competentes, como a Secretaria de Educação e os Centro de Formação e Atualização dos Profissionais da Educação Básica de Mato Grosso (CEFAPRO), projetos concisos, que demonstrem a necessidade de a unidade escolar ser informatizada, com Laboratório de Informática Educacional e outros recursos tecnológicos que fazem parte das salas de multimeios, bem como buscar formação para que esses recursos sejam utilizados da forma eficaz. Almeida e Alonso (2007, p. 30) destacam:

[...] o mundo mudou, as pessoas vivem em outra época e as escolas precisam estar atentas a isso. Portanto, o gestor tem o papel fundamental de propor novas formas de organizar o trabalho escolar, tornando esse ambiente o mais próximo possível dessa realidade. Para tanto, ele precisa estar preparado para encarar os desafios que se impõem à educação e à própria escola.

A escola com visão futurista possui ferramentas tecnológicas que atualmente substituem o caderno e o lápis, portanto a formação continuada contribui de forma significativa para o desenvolvimento do conhecimento profissional do professor, privilegiado por permitir a aproximação entre os processos de mudança no contexto da escola (PIMENTA, 2005).

Diante desse cenário, é evidente a importância da formação continuada dos profissionais da educação, proporcionando um ambiente em que os saberes e práticas vão se ressignificando, em busca de um espaço de produção de novos conhecimentos, de repensar e refazer a prática do professor, da gestão diante das novas habilidades e competência a serem desenvolvidas pelo docente. Para Krasilchik (2008, p. 184),

[...] pelas suas difíceis condições de trabalho, os docentes preferem os livros que exigem menos esforço e que reforçam uma metodologia autoritária e um ensino teórico [...]. O docente, por falta de autoconfiança, de preparo, ou por comodismo, restringe-se a apresentar aos alunos, com o mínimo de modificações, o material previamente elaborado por autores que são aceitos como autoridades. Apoiado em material planejado por outros e produzido industrialmente, o professor abre mão de sua autonomia e liberdade, tornando simplesmente um técnico.

Precisamos ir além do quadro negro, o giz e as quatro paredes da sala de aula, pois a aprendizagem não se limita apenas a esse espaço. Os tempos mudaram, apenas o discurso do professor já não é suficiente para prender a atenção do aluno hoje em dia, ele precisa inovar, buscar novas alternativas, tornar suas aulas interativas, mas para isso é necessário se atualizar também, quebrar tabus e sair da zona de conforto.

Pimenta (2005) afirma que o saber docente não é formado apenas da prática, sendo também nutrido pelas teorias da educação, pois dota os sujeitos de variados pontos de vista para 
uma ação contextualizada e recontextualizada, oferecendo perspectivas de análise para que os professores compreendam os diversos contextos vivenciados por eles no exercício da profissão.

Os recursos didáticos são de grande importância para a aprendizagem dos alunos, pois possibilita uma aprendizagem significativa. Diante da significação dos recursos didáticos para o processo de ensino, o professor deve ser criativo e pesquisador. Os recursos didáticos devem auxiliar o aluno a pensar. Libâneo (1994), afirma que a escolha deles depende dos objetivos da aula, dos conteúdos específicos, das características dos alunos quanto à capacidade de assimilação conforme idade e nível de desenvolvimento mental.

Diante disso, podemos dizer que Recursos didáticos são ferramentas que o professor utiliza durante as suas aulas e estas possibilitam uma maior compreensão dos alunos em relação ao conteúdo aplicado, visto que auxiliam muito na didática, de acordo com o plano de ensino proposto pelo professor.

No entanto, a sociedade está em constante mudança, a globalização vem causando impactos em vários setores, inclusive na educação, a escola deve estar sempre conectada às mudanças que ocorrem ao seu redor. Deve-se fazer uma reflexão da nossa prática enquanto educadores e aceitar que tais mudanças não ocorrem somente pela incorporação de novos paradigmas de comportamentos da sociedade, mas também porque a escola não está conseguindo alcançar os resultados esperados, então por que não auxiliar o aluno a alcançar seu potencial máximo, aproveitando todos os benefícios educativos que os recursos tecnológicos podem oferecer? Sobre isso, Sampaio e Leite argumentam:

A preocupação com o impacto que as mudanças tecnológicas podem causar no
processo de ensino-aprendizagem impõe a área da educação a tomada de posição entre
tentar compreender as transformações do mundo, produzir o conhecimento
pedagógico sobre ele auxiliar o homem a ser sujeito da tecnologia, ou simplesmente
dar as costas para a atual realidade da nossa sociedade baseada na informação.
(SAMPAIO e LEITE, 2000, op cit SANTOS, 2012, p. 9).

Saber como nossos alunos estão utilizando todos esses recursos tecnológicos e orientálos a tirar o máximo de proveito dessas magníficas ferramentas é uma das nossas funções como educadores. Soares (2011), faz uma reflexão no que se refere aos benefícios reais das práticas educacionais mediadas pelas TICs (Tecnologias da Informação e Comunicação), uma vez que o mundo contemporâneo discute cada vez mais a adesão ou rejeição à informática e suas aplicações nos diversos contextos sociais.

Contrapondo as ideias de Soares, Moran observa que

O reencantamento, enfim, não reside principalmente nas tecnologias — cada vez mais sedutoras — mas em nós mesmos, na capacidade em tornar-nos pessoas plenas, num 
mundo em grandes mudanças e que nos solicita a um consumismo devorador e pernicioso. É maravilhoso crescer, evoluir, comunicar-se plenamente com tantas tecnologias de apoio. É frustrante, por outro lado, constatar que muitos só utilizam essas tecnologias nas suas dimensões mais superficiais, alienantes ou autoritárias. O reencantamento, em grande parte, vai depender de nós. (MORAN, 1994, p.26)

Os recursos tecnológicos foram implantados nas escolas não para facilitar o trabalho dos educadores, mas para que o educando aprendesse a partir da realidade do mundo e principalmente para que esse indivíduo consiga então agir sobre essa realidade, transformandoa e assim transformando a si próprio. O computador e a Internet atraem a atenção dos alunos, desenvolvendo neles habilidades para captar a informação. Essa informação manifesta-se de forma cada vez mais interativa e cada vez mais depressa, que os envolvidos no processo de ensino, muitas vezes, não conseguem assimilar.

Pierre Lévy (1999), afirma que a rede de computadores é um universo que permite às pessoas conectadas construir e partilhar inteligência coletiva sem submeter-se a qualquer tipo de restrição político-ideológico, ou seja, a internet é um agente humanizador, porque democratiza a informação, e humanitário, porque permite a valorização das competências individuais e a defesa dos interesses das minorias. Segundo Levy (1999, p.50), as tecnologias não são positivas ou negativas; antes, dependem da utilização que se faz delas e do contexto em que elas se inserem.

Segundo Xavier (2005), as novas gerações têm adquirido o letramento digital antes mesmo de ter se apropriado completamente do letramento alfabético ensinado na escola. Esta intensa utilização do computador para a interação entre pessoas a distância tem possibilitado que crianças e jovens se aperfeiçoem em práticas de leitura e escrita diferentes das formas tradicionais de letramentos e alfabetizações. Essas inúmeras modificações nas formas e possibilidades de utilização da linguagem em geral são reflexos incontestáveis das mudanças tecnológicas que vêm ocorrendo no mundo desde que os equipamentos informáticos e as novas tecnologias de comunicação começaram a fazer parte intensamente do cotidiano das pessoas.

Os professores precisam atualizar constantemente suas práticas pedagógicas, diante da diversidade de público e das dificuldades enfrentadas dentro da política educacional. Stainback e Stainback (1999) afirmam que boas escolas são aquelas que se preocupam com a satisfação e aprendizagem de todas as pessoas, ou seja, dos profissionais da educação, dos alunos, da comunidade escolar e dos funcionários dentro do ambiente escolar.

Moran (2007) defende a ideia de que as tecnologias não substituíram os professores, mas irão permitir que várias tarefas e funções possam ser transformadas. Para Valente (1993), 
o professor deixa de ser o repassador do conhecimento para ser o criador de ambientes de aprendizagem e facilitador do processo pelo qual o aluno adquire conhecimento. Portanto, o professor continua tendo um papel fundamental, não como transmissor do conhecimento, mas sim como mediador no acesso e organização dos processos que envolvem a aprendizagem. Segundo Almeida (2007, p. 159),

A incorporação de uma tecnologia aos processos educacionais passa pela compreensão das características constitutivas desse novo meio, de suas potencialidades e limitações em relação às formas de interação e construção de significados. Assim, torna-se necessário que o professor utilize a tecnologia na condição de sujeito ativo, protagonista da ação, de modo que possa analisar a efetividade das contribuições desse suporte para a criação de experiências educativas significativas e relevantes para os aprendizes.

A inserção das tecnologias constitui um desafio para escolas e professores. Neste contexto, é fundamental que os alunos saibam fazer uma seleção de informação e saibam utilizar esses recursos a seu favor.

Para Martins (2009) "não se trata de tecnologizar a escola, mas de integrar na pedagogia formas digitais de conhecer. Portanto, não se trata apenas de trazer esses recursos didáticos para a escola, eles devem ser utilizados pedagogicamente. As tecnologias educacionais devem fazer com que o aluno se torne autônomo e o professor deve ser um pesquisador. De acordo com Straub (2009, p. 60):

A construção do conhecimento do aluno deve ocorrer por meio de um processo interativo deste com o professor, no qual o professor será o mediador do processo ensino-aprendizagem através da midiatização das tecnologias de informação e de comunicação, principalmente o computador e a internet.

A escola deve assegurar aos alunos uma aprendizagem significativa e conectada à sua realidade, e sem dúvida nenhuma para isso acontecer é preciso modernizar a escola, criando condições físicas e estruturais que favoreçam o sucesso dos alunos e consolidem o uso das tecnologias educacionais para promover a aprendizagem.

Uma das principais dificuldades de se incorporar as tecnologias de informação e comunicação no processo de ensino, é o fato de o professor ser ainda apontado como o detentor de todo conhecimento, para eles é um desafio mudar sua forma de conceber e pôr em prática o ensino, através de uma nova ferramenta. Para Imbérnom (2010, p.36):

Para que o uso das TIC signifique uma transformação educativa que se transforme em melhora, muitas coisas terão que mudar. Muitas estão nas mãos dos próprios professores, que terão que redesenhar seu papel e sua responsabilidade na escola atual. Mas outras tantas escapam de seu controle e se inscrevem na esfera da direção da escola, da administração e da própria sociedade. 
No cenário atual, diante das tecnologias apresentadas aos alunos, o professor tem o papel de interventor dessa nova forma de ensino, dando o suporte necessário ao uso adequado e responsável dos recursos tecnológicos. Para que isso aconteça, o professor deve buscar, ainda em sua formação, se atualizar, não só dentro de sua especialidade, mas também, em relação às tecnologias que possam auxiliar em suas práticas pedagógicas.

Para Moran, "cada docente pode encontrar sua forma mais adequada de integrar as várias tecnologias e os muitos procedimentos metodológicos. Mas também, é importante que amplie, que aprenda a dominar as formas de comunicação interpessoal/grupal e as de comunicação audiovisual/telemáticas." (MORAN, 2000, p. 32).

Segundo Moran (2007), o professor é mais importante do que nunca nesse processo de inclusão da internet na educação, pois ele precisa aprimorar seus conhecimentos sobre essa tecnologia para introduzi-la na sala de aula, no seu dia a dia, da mesma forma que o professor, que um dia introduziu o primeiro livro em uma escola e teve de começar a lidar de modo diferente com o conhecimento - sem deixar as outras tecnologias de comunicação de lado. Continuaremos a ensinar e a aprender pela palavra, pelo gesto, pela emoção, pela afetividade, pelos textos lidos e escritos, pela televisão, mas agora também pelo computador, pela informação em tempo real, pela tela em camadas, em janelas que vão se aprofundando as nossas vistas.

[...] a implantação da informática como auxiliar do processo de construção do conhecimento implica mudanças na escola que vão além da formação do professor. É necessário que todos os segmentos da escola - alunos, professores, administradores e comunidades de pais - estejam preparados e suportem as mudanças educacionais necessárias para a formação de um novo profissional. Nesse sentido, a informática é um dos elementos que deverão fazer parte da mudança, porém essa mudança é mais profunda do que simplesmente montar laboratórios de computadores na escola e formar professores para utilização dos mesmos. (VALENTE, 1999, p. 4).

Mais uma vez voltamos à importância da formação de educadores, para atualizar e qualificar é necessário capacitar os professores, técnicos e apoio, buscando conhecer e discutir formas de utilização de tecnologias no campo educacional.

Veiga (2008) preconiza a necessidade da formação do educador, e salienta que é preciso compreender o papel da docência, propiciando uma profundidade cientifico - pedagógica que capacite o educador a enfrentar questões fundamentais da escola como instituição social, uma prática social que deve ser baseada na reflexão e crítica, que se torna o centro de uma formação continuada que resultará em uma aprendizagem significativa. 


\section{Procedimentos do Metodológicos}

Durante a pesquisa científica descobrimos um universo encantador de métodos e práticas pedagógicas, além de aprender e compartilhar conhecimentos na busca de respostas para várias indagações relacionadas ao cotidiano escolar. A presente pesquisa é de natureza aplicada. Appolinário (2011, p. 146), afirma que a pesquisa aplicada é utilizada para "resolver problemas ou necessidades concretas e imediatas", que nesse caso, é analisar as contribuições dos recursos tecnológicos utilizados na Escola Estadual Conquista D`Oeste e analisar como eles podem se converter em um instrumento significativo e eficaz para o processo de ensino aprendizagem.

Utilizou-se como base teórica a pesquisa bibliográfica e documental. Segundo Boccato (2006, p. 266), a pesquisa bibliográfica busca a resolução de um problema (hipótese) por meio de referenciais teóricos publicados, analisando e discutindo as várias contribuições científicas. Esse tipo de pesquisa trará subsídios para o conhecimento sobre o que foi pesquisado, como e sob que enfoque e/ou perspectivas foi tratado o assunto apresentado na literatura científica.

A análise documental, de acordo com Gil (2008), é muito parecida com a bibliográfica. A diferença está na natureza das fontes, pois esta vale-se de materiais que não receberam ainda um tratamento analítico, ou que ainda podem ser reelaborados de acordo com os objetos da pesquisa. A pesquisa bibliográfica foi realizada em diversas literaturas que tratam da problemática, já a pesquisa documental foi realizada no Projeto Político Pedagógico - PPP, nos Planos de aula e Planos de Ação elaborados pelos professores, na Base Nacional Comum Curricular - BNCC e nos Documentos de Referência Curricular do Estado do Mato Grosso DRCs.

Quanto à abordagem, a pesquisa pode ser classificada como qualitativa, pois aspiramos provocar os autores da educação no sentido de que façam uma reflexão quanto às metodologias utilizadas por eles em sala de aula, e com isso compreendam alguns fatores como evasão, déficit de aprendizagem e outros. Segundo Gil (2008), essa abordagem proporciona melhor compreensão do problema, pois pode gerar hipóteses e fornecer elementos para a construção de instrumentos de coleta de dados.

A pesquisa é exploratória, pois segundo Gil (2008), a pesquisa exploratória objetiva principalmente desenvolver, esclarecer e modificar conceitos e ideias, tendo em vista a formulação de problemas mais precisos ou hipóteses pesquisáveis para estudos posteriores. 
Além disso, essa investigação se caracteriza como pesquisa de campo, pois desenvolveu-se por meio de observações e uso de questionários.

Quanto aos procedimentos, técnicas ou tipos de pesquisa, a pesquisa pode ser classificada como estudo de caso. O estudo de caso é caracterizado pelo estudo profundo e exaustivo de um ou poucos objetos, de maneira a permitir o seu conhecimento amplo e detalhado, tarefa praticamente impossível mediante os outros tipos de delineamentos considerados (GIL, 2008, p. 57 e 58).

Os dados foram coletados entre os meses de fevereiro e maio do ano de 2021, período de aulas on-line, devido à pandemia do Covid-19. O projeto que subsidia esse artigo foi submetido ao comitê de ética, sendo aprovado em agosto de 2020. A pesquisa teve como sujeitos, 14 (quatorze) professores que atuam no Ensino Médio na Escola Estadual Conquista D’Oeste. Para coleta de dados foi utilizado um questionário composto de perguntas abertas e de múltipla escolha, aplicado pelo Google Forms. Outro método de coleta de dados utilizado foi a observação, realizada in loco e através do Google Meet. A observação permitiu fazer uma análise de como os professores estão utilizando os recursos tecnológicos disponíveis na escola. Além de observar se as respostas obtidas no questionário estão de acordo com as práticas docentes dos sujeitos da pesquisa.

Para análise de dados utilizamos como forma de tratamento e a interpretação de dados, a Triangulação de fontes, pois de acordo com Denzin e Lincoln (2006, p.19), "uso de múltiplos métodos, ou da triangulação, reflete uma tentativa de assegurar uma compreensão em profundidade do fenômeno em questão".

\section{Resultados E Discussões}

Atualmente é muito discutida a inserção das tecnologias como recurso didático dentro do cenário educacional e a sua importância para uma aula interativa e dinâmica, em que o aluno produza conhecimento de forma autônoma.

Um fator que influencia muito na aceitação ou não dos recursos tecnológicos como ferramenta de aprendizagem, é o tempo de atuação dos professores na educação. Segundo dados obtidos através do questionário, 42,9\% dos participantes da pesquisa, o que corresponde a seis (6) professores, atuam na educação há mais de quinze (15) anos, isso significa que a maioria desses profissionais foram alfabetizados ou tiveram sua escolarização embasadas na tendência tradicional. 
Figura 1 - Tempo de atuação dos professores da EECDO na Educação

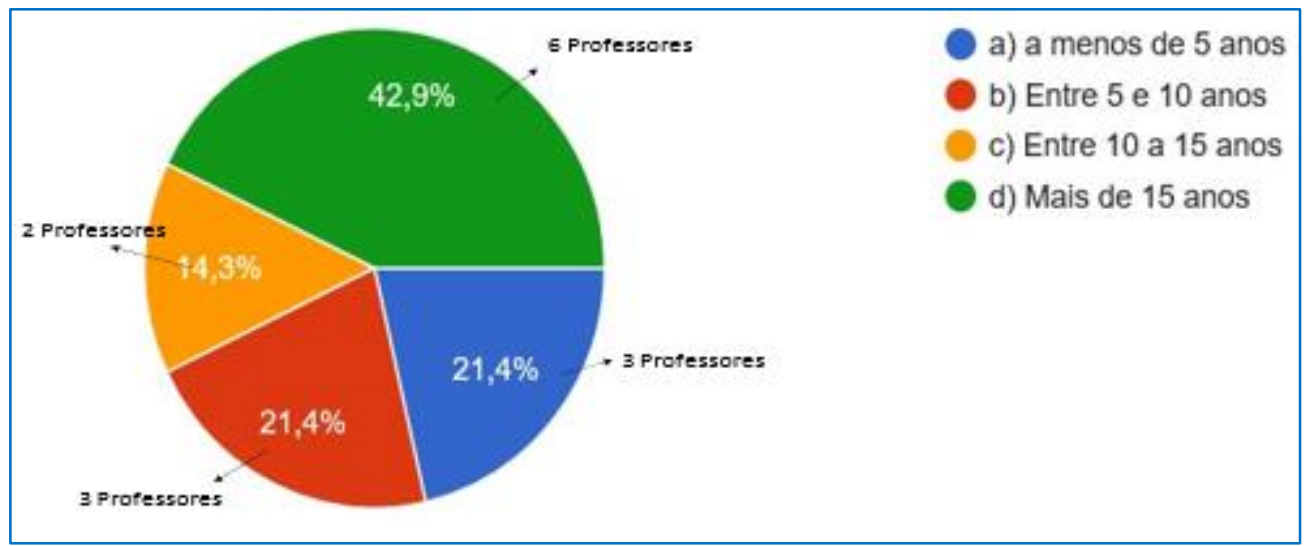

Fonte: Dados da Pesquisa (2021).

Como a maioria dos professores atuam há mais de dez (10) anos na educação, a maioria deles pertencem à denominada Geração X, ou seja, nasceram em uma época em que os recursos tecnológicos eram para poucos. Portanto, revolucionar, inovar suas metodologias de ensino para esses professores é muito mais difícil, pois causa desconforto e medo ${ }^{1}$.

Nesse sentido, Tardif (2014) afirma que o professor vai construindo sua identidade e agregando a ela saberes sociais, culturais e profissionais. Assim, mudar a forma de pensar, quebrar paradigmas pode demorar algum tempo. Quanto aos saberes docentes, o referido autor esclarece que estes são oriundos de livros didáticos, de programas escolares, de conteúdos e da própria experiência, Tardif ainda apresenta esses saberes em quatro categorias: saberes profissionais, disciplinares, curriculares e experienciais.

Tardif (2014) acrescenta que os saberes experienciais são adquiridos na prática docente, os saberes profissionais são adquiridos na formação inicial ou continuada dos professores, os saberes disciplinares são oriundos de diversos campos do conhecimento, os saberes disciplinares seriam como saberes que "emergem da tradição cultural e grupos sociais produtores de saberes"(TARDIF, 2014, p.38), já os saberes curriculares correspondem aos "discursos, objetivos, conteúdos e métodos a partir dos quais a instituição escolar categoriza e apresenta os saberes sociais por ela definidos e selecionados como modelos da cultura erudita e de formação para a cultura erudita" (idem, ibidem).

\footnotetext{
${ }^{1}$ GERAÇÃO X, Y E BABY BOOMERS: Um Desafio Atual para uma Organização do Segmento Tecnológico. Disponível em: https://periodicoscientificos.ufmt.br/ojs/index.php/repad/article/view/6003/4278. Acesso em: 05/06/2021.
} 
Durante a observação verificou-se que os professores mais jovens que atuam a menos tempo na educação possuem maior facilidade para inserir recursos tecnológicos em suas aulas, eles também detêm um domínio maior da linguagem tecnológica utilizada pelos alunos.

Nota-se, contudo, que a educação não pode permanecer alheia às mudanças que acontecem no cenário econômico e social, e é função do professor desenvolver competências e habilidades em seus discentes, preparando-os para viver e atuar de forma crítica nessa sociedade tecnológica que está em constante evolução.

A observação também permitiu verificar a resistência à mudança, ao novo, durante as aulas remotas no período da pandemia Covid 19. Dos quatorze (14) professores que participaram da pesquisa, sete (7) ministraram suas aulas pelo Google Meet, cinco (5) ministraram suas aulas apenas pelo WhatsApp e dois (2) apenas com apostilas, pois são professoras nas salas anexas na Reserva Indígena Sararé, nesse caso específico, os alunos não têm acesso à Internet e as professoras atendem os alunos a cada quinze (15) dias, fazendo atendimento individual, entregando e recolhendo as apostilas. Vale a pena salientar que a entrada na aldeia no período da pandemia é autorizada pela Fundação Nacional do Índio (FUNAI), para essa permissão exigiram exame comprovando que as professoras testaram negativo para a Covid 19 todas as vezes que essas entraram nas aldeias (Aldeia Serra da Borda e Sararé Central).

Durante o período de observação verificou-se que dos sete (7) professores que ministraram aulas pelo aplicativo Google Meet, quatro (4) utilizam metodologias que tinham como base o protagonismo dos alunos no processo de aprendizagem, as demais aulas foram expositivas com slides em que o ensino permanece centrado no professor. O medo e a incerteza de como utilizar novas metodologias de ensino, incluindo as que envolvem tecnologias da informação e comunicação, acrescidos da falta de tempo, formação, fazem com que os professores optem pelo tradicional.

Quando perguntado: você procura incluir recursos tecnológicos como material didático durante a sua aula? Se sim, quais recursos e como você utiliza os mesmos? Treze (13) responderam que utilizam algum tipo de recurso tecnológico, apenas um (1) disse que não. Cerqueira e Ferreira (2007, p. 01.) definem como recursos didáticos:

[...] são todos os recursos físicos, utilizados com maior ou menor frequência em todas as disciplinas, áreas de estudo ou atividades, sejam quais forem as 13 técnicas ou métodos empregados, visando auxiliar o educando a realizar sua aprendizagem mais eficientemente, constituindo-se num meio para facilitar, incentivar ou possibilitar o processo ensino-aprendizagem. 
Ao padronizar as respostas da questão obtivemos o seguinte resultado:

Figura 2 - Recursos tecnológicos utilizados pelos professores da EECDO

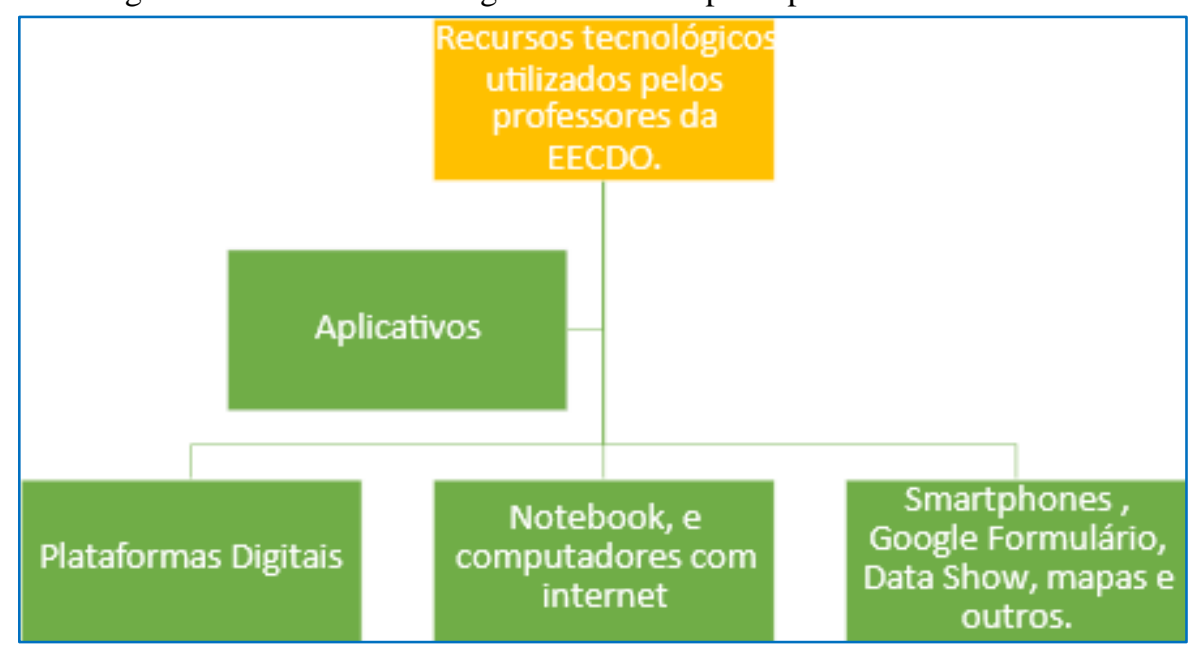

Fonte: Dados da Pesquisa (2021)

Observa-se, no esquema acima, a menção a vários recursos tecnológicos, contudo dois estavam mais evidentes: o uso de aplicativos e de plataformas digitais. Dez (10) professores disseram que utilizam algum aplicativo em suas aulas e três (3) utilizam plataformas digitais:

[...] "sempre que possível, utilizo laboratórios virtuais, aplicativos para produção de mapa conceitual, para produção de murais ...” (P14).

[...] "aplicativos para edição de vídeos para apresentações" [...] (P11).

[...] "o uso de algumas plataformas, projeto de xadrez para estimular o raciocínio rápido, concentração e estratégias.” (P9).

[...] "ferramentas de comunicação, aplicativo e google sala de aula." (P13).

"Vídeos-aulas, apps que ajudam na leitura, apps de produção de HQs como o Pixton, o Canva para construção de infográficos, cartazes e folders informativos." (P4).

"Nesses dias, por causa da pandemia, estamos fazendo uso de aparelhos de tecnologias de informação e comunicação e com uso de internet." (P3).

Apenas um (1) professor disse que utiliza smartphone/celular. "Pesquisa em biblioteca integradora, jogos e aplicativos para smartphones para desenvolver atividades como infográficos, mapa mental, quadrinhos..." (P10), o que chama a atenção, pois o celular é a principal ferramenta de mediação de aprendizagem nesse momento de pandemia Covid 19.

O uso do celular como recurso pedagógico é uma temática que vem sendo muito discutida entre os professores. Porém, baseados em relatos e estudos de professores que utilizam o celular em sala de aula como ferramenta de ensino, alguns professores da EECDO passaram a utilizá-lo como recurso pedagógico.

Embasados em pesquisas sobre a importância do uso do celular como recurso pedagógico, a Organização das Nações Unidas para a Educação, a Ciência e a Cultura 
(UNESCO) desenvolveu diretrizes para auxiliar na elaboração de políticas públicas com o objetivo de compreender melhor o significado de aprendizagem móvel e quais os benefícios que esse método de aprendizagem pode trazer para o ambiente escolar.

\begin{abstract}
Atualmente, um volume crescente de evidências sugere que os aparelhos móveis, presentes em todos os lugares - especialmente telefones celulares e, mais recentemente, tablets - são utilizados por alunos e educadores em todo o mundo para acessar informações, racionalizar e simplificar a administração, além de facilitar a aprendizagem de maneiras novas e inovadoras (UNESCO, 2014, p. 7).
\end{abstract}

Para Nagumo (2014), o uso do celular pode contribuir com o processo de aprendizagem, e a escola pode elaborar regras, fazer acordos didáticos para que ocorra o uso responsável desses aparelhos. O autor defende que a escola deve buscar entender a evolução tecnológica como uma questão social e cultural na qual os alunos estão inseridos.

As observações comprovaram as afirmativas relacionadas à questão supracitada, todos os professores utilizam recursos tecnológicos

Entre os recursos tecnológicos mais utilizados, de acordo com a observação, estão o celular e o notebook, dispositivos utilizados para acessar o WhatsApp ou o Google Meet. Três (3) professores utilizaram a lousa interativa on-line, dois (2) utilizaram aplicativos, o Mentimeter para criar mapa mental com as principais ideias da aula e o Pixton, em que os alunos produziram histórias ou modificaram o final de histórias já existentes de filmes, livros ou outra história que desejavam outro final. Dez (10) professores utilizaram vídeos da internet ou produzidos por eles mesmos como complementação pedagógica.

Sampaio e Leite (2000) acrescentam que as transformações tecnológicas que vêm ocorrendo no mundo, impõe à área de educação duas alternativas, a de utilizar essas ferramentas para produzir conhecimento pedagógico, auxiliando os educandos a se tornarem sujeitos tecnológicos, ou pode simplesmente dar as costas e ficar alheia à sociedade, que atualmente é baseada em tecnologias de comunicação e informação. Leal, Miranda e Nova (2019, p. 36) corroboram "Informação e conteúdo são aspectos essenciais para a formação do indivíduo, embora não seja bastante apenas saber selecionar as informações, mas é preciso saber como e onde adquiri-las, no momento em que elas forem necessárias". Para que os recursos tecnológicos façam parte da vida escolar, eles devem ser utilizados de forma correta, somente assim a tecnologia será realmente incorporada no currículo escolar.

Ao questionar os professores a respeito dos recursos didáticos, o quanto eles os julgam importantes para ministrar uma boa aula, todos, com palavras específicas, disseram que esses 
recursos são importantes, pois auxiliam de forma significativa o processo de aprendizagem e além disso é uma forma de tornar as aulas dinâmicas e atrativas.

"Acredito que os recursos como o próprio nome diz, servem para dar um aporte e melhorar a forma como trabalhamos e também ajudam a tornar as aulas mais dinâmicas facilitando o acesso à aprendizagem.” (P4)

"São fundamentais, em alguns casos, indispensáveis para uma aula mais dinâmica." (P10)

"Eu julgo essencial para ministrar uma boa aula, pois, temos que tornar a aula mais atrativa ao aluno." (P7)

"Fundamentais, pois auxiliam o Professor na condução de uma aula mais dinâmica e que desperta o estudante para o conhecimento." (P12)

"Nesse momento que estamos vivendo, com aulas remotas, os materiais didáticos entram em nossa sala de aula, de uma forma que possam auxiliar nossos alunos [...]" (P11).

Os recursos didáticos podem tornar a aula mais interessante e atrativa, o conteúdo pode ficar mais relevante e envolvente quando se utiliza o material didático adequado, seja no modelo presencial de ensino ou no remoto. Apesar de os professores relatarem que os recursos didáticos são essenciais para ministrar uma boa aula, na observação constatou-se que 5 (cinco) destes utilizaram apenas a apostila para ministrar suas aulas.

"Recursos didáticos são importantes, porém não são primordiais, podemos ensinar com criatividade quando não temos tantos recursos.” (P9). Sabemos que os recursos didáticos em escolas públicas são escassos, e o que dizer dos recursos de tecnologias de comunicação e informação? Estes são ainda menos encontrados. O computador e a Internet atraem a atenção dos alunos, desenvolvendo neles habilidades para captar a informação. Essa informação manifesta-se de forma cada vez mais interativa e cada vez mais rápida, sendo que os envolvidos no processo de ensino, muitas vezes, não conseguem assimilar.

Quanto ao uso de tecnologias digitais como recurso didático, Ganzela enfatiza que a “combinação de metodologias ativas com tecnologias digitais móveis é hoje estratégica para a inovação pedagógica" (GANZELA, 2018, p. 52).

O professor deve se empenhar para dar uma aula de qualidade, falar em utilizar celular, o computador é fácil quando se é professor de escola particular. Nas escolas públicas encontramos dificuldades até para utilizar o celular, pois nem todos os alunos têm o aparelho e se tem, poucos possuem internet, portanto fica a questão: Como promover uma educação de qualidade, sem promover a equidade nas escolas públicas brasileiras?

O Governo Federal e Estadual tem buscado implantar Políticas Públicas que possam desenvolver ações para incorporação de tecnologias de informação e comunicação nas escolas 
públicas, com aquisição de equipamentos e formação em parceria com vários órgãos educacionais, um exemplo é o Programa Nacional de Tecnologia Educacional (ProInfo), integrado aos CEFAPROs ${ }^{2}$. O programa leva às escolas computadores, recursos digitais $\mathrm{e}$ conteúdos educacionais. Em contrapartida, estados, Distrito Federal e municípios devem garantir a estrutura adequada para receber os laboratórios e capacitar os educadores para uso das máquinas e tecnologias. Diante da inserção da tecnologia na educação, despertou-nos o interesse numa discussão que problematiza os reflexos do avanço tecnológico na aprendizagem do aluno.

Outro programa que merece destaque é o de Inovação Educação Conectada do Ministério da Educação ${ }^{3}$, elaborado em quatro dimensões interligadas entre si: visão, formação, recursos educacionais digitais e infraestrutura, seu objetivo é apoiar a universalização do acesso à internet de alta velocidade, por via terrestre e satelital e fomentar o uso de tecnologia digital na Educação Básica. No entanto, o recurso para contratação de Internet é insuficiente, a Escola Estadual Conquista D’Oeste recebeu no final do ano de 2019, dez mensalidades de R $\$ 300,00$ reais para atender 545 alunos.

Quando perguntado: Os gestores da Escola Estadual Conquista D'Oeste apoiam e dão suporte à essas novas metodologias de ensino, auxiliando no planejamento e participando ativamente dos projetos e planos de ação? Todos os professores responderam que sim, e isso se confirmou durante a observação, as coordenadoras pedagógicas estão sempre acompanhando as aulas, dando suporte pedagógico.

Apesar de estar contemplado na Lei de Diretrizes e Bases da Educação Nacional - LDB, uma formação inicial eficaz e contemporânea, isso não acontece, daí então a importância da formação continuada e de termos professores pesquisadores. $\mathrm{O}$ documento elaborado pelo Ministério da Educação (MEC) deixa isso bem claro em seu texto, [...] delineiam um cenário educacional com exigências para cujo atendimento os professores não foram nem estão sendo preparados (BRASIL, 2000, p. 5).

\footnotetext{
${ }^{2}$ Ministério da educação - MEC. ProInfo- Apresentação. Disponível em: http://portal.mec.gov.br/index.php?option=com_content\&view=article\&id $=244 \& I t e m i d=462 \& \mathrm{msg}=1 \& \mathrm{l}=\mathrm{aW} 5 \mathrm{k}$ ZXgucGhwP29wdGlvbj1jb21fY29udGVudCZ2aWV3PWJ1c2NhZ2VyYWwmSXRlbWlkPTE2NCZwYXJhbX Nbc2VhcmNoX3JlbGV2YW5jZV09cHJvaW5mbyZkPXMmcGFyYW1zW2RIXT0mcGFyYW1zW2F0ZV09Jn BhcmFtc1tjYXRpZF09JnBhcmFtc1tzZWFyY2hfbWV0aG9kXT1hbGwmcGFyYW1zW29yZF09cHI= . Acesso em: 13 de junho de 2021.

${ }^{3}$ Ministério da educação - MEC. Inovação tecnológica Impulsionando a Educação Brasileira. Disponível em: http://educacaoconectada.mec.gov.br/. Acesso em: 13 de junho de 2021.
} 
Como pode-se observar, os professores têm participado de cursos de formação oferecidos pelo CEFAPRO, pelo órgão central SEDUC, alguns professores até pagam cursinhos de formação a distância, no entanto quando falamos em formação continuada não nos referimos somente a cursinhos, estamos falando de programas de especialização, mestrado e doutorado, os quais estão garantidos na LDB. De acordo com Dourado (2015),

\begin{abstract}
A formação continuada deve se dar pela oferta de atividades formativas diversas incluindo atividades e cursos de atualização e extensão, cursos de aperfeiçoamento, cursos de especialização, cursos de mestrado e doutorado que agreguem novos saberes e práticas, articulados às políticas e gestão da educação, à área de atuação do profissional e às instituições de educação básica, em suas diferentes etapas e modalidades. A formação continuada deve se efetivar por meio de projeto formativo que tenha por eixo a reflexão crítica sobre as práticas e o exercício profissional e a construção identitária do profissional do magistério (DOURADO, 2015, p. 313).
\end{abstract}

Diante do exposto, vê-se, portanto, a necessidade de preparar os professores para o uso dessa tecnologia no cotidiano escolar, uma vez que a maioria desses profissionais ainda não possuem habilidades para utilização das tecnologias digitais. Para isso, faz-se necessário políticas públicas voltadas para a formação de professores, como a criação de mais programas de especialização, mestrado e doutorado em universidades públicas, e isso é responsabilidade dos gestores municipais, estaduais e federal.

\title{
5 CONSIDERAÇÕES FINAIS
}

Considera-se, portanto, que no atual contexto escolar é impensável fazermos algumas tarefas sem alguns recursos tecnológicos, entendendo que educação, não se refere apenas à sala de aula, mas de forma geral, do administrativo na secretaria, na biblioteca, no laboratório de informática, do professor em relação a registros de diários e pesquisas para planejar uma aula atrativa, do apoio com seus registros e planilhas.

Todos os profissionais da escola devem buscar, através da formação continuada, mecanismos para acompanhar esse desenvolvimento tecnológico e aplicá-los a favor da educação de forma a promover uma aprendizagem significativa e prazerosa.

Diante do exposto, as tecnologias educacionais devem ser utilizadas como uma ferramenta de auxílio na aquisição de conhecimento, visto que fazem parte do cotidiano dos alunos, cabe então à escola e ao professor democratizar e orientar os alunos no uso da internet de modo a conduzi-los ao processo de construção de aprendizagem, possibilitando ao professor ser mediador, isto é, acompanhar e sugerir atividades, estimulando a busca de um novo saber. 
Já sabemos que essa tecnologia, se bem utilizada, pode beneficiar o trabalho pedagógico na escola, inovando e trazendo propostas dinâmicas para que a construção do saber se torne prazerosa e estimulante.

Além disso, nos dois últimos anos que configuram o contexto pandêmico, percebe-se a necessidade de se promover a igualdade e equidade dentro do ambiente escolar. $\mathrm{O}$ acesso a esses recursos tecnológicos deve ser uma realidade para todos os alunos, somente assim teremos uma educação humanizada e igualitária.

Ao finalizar, conclui-se que cabe a nós, educadores, assimilar a melhor forma de inserir esses recursos tecnológicos no cotidiano escolar, buscando inovar e tornar as aulas e o próprio ambiente escolar mais atrativos. Portanto, é imprescindível a participação de todos os segmentos da comunidade escolar para fazer com que esses recursos tecnológicos façam parte do cotidiano da escola, é fundamental a formação de todos os profissionais que atuam na educação desde o administrativo até o setor pedagógico. Essa formação deve ser proporcionada pelos poderes públicos em todas as suas esferas, de acordo com o Artigo 62, da Lei de Diretrizes e Bases da Educação Básica (LDB).

Educar, portanto, não pode implicar tão somente transmissão de informações, assegurando que elas sejam retidas na memória para serem utilizadas em outras oportunidades, uma vez que, a qualquer momento, elas poderão deixar de ser importantes e significativas. Concluímos, portanto, que as tecnologias de informação e comunicação possibilitam ao indivíduo ter acesso a milhares de informações e pode servir como ferramenta de aprendizagem, como espaço de socialização, gerando saberes e conhecimentos científicos.

\section{REFERÊNCIAS}

ALMEIDA, Maria Elizabeth Bianconcini de; RUBIM, Lígia Cristina Bada. O papel do gestor escolar na incorporação das TIC na escola: experiências em construção e redes colaborativas de aprendizagem. São Paulo: PUC-SP, 2004.

ALMEIDA, Maria Elizabeth Bianconcini de; ALONSO, Myrtes (orgs). Tecnologias na Formação e na Gestão Escolar. São Paulo: Avercampp, 2007.

APPOLINÁRIO, Fabio. Dicionário de Metodologia Científica. 2. ed. São Paulo: Atlas, 2011. 295p.

ARAUJO, Elaine Vasquez Ferreira de; VILAÇA, Márcio Luiz Corrêa. Sociedade Conectada: Tecnologia, Cidadania e Infoinclusão. In: ARAUJO, Elaine Vasquez Ferreira de; VILAÇA, Márcio Luiz Corrêa (orgs). Tecnologia, Sociedade e Educação na Era Digital. Duque de Caxias, RJ: UNIGRANRIO, 2016. 
BOCCATO, Vera Regina Casari. Metodologia da pesquisa bibliográfica na área odontológica e o artigo científico como forma de comunicação. Rev. Odontol. Univ. Cidade São Paulo, São Paulo, v. 18, n. 3, p. 265-274, 2006.

BRASIL. Lei de Diretrizes e Bases da Educação Nacional. 1996. Disponível em: http://www.planalto.gov.br/ccivil_03/leis/19394.htm . Acesso em: 28 de junho de 2021.

BRASIL. Ministério da Educação. PROPOSTA DE DIRETRIZES PARA A FORMAÇÃO INICIAL DE PROFESSORES DA EDUCAÇÃO BÁSICA, EM CURSOS DE NÍVEL SUPERIOR. 2000. Disponível em:

http://portal.mec.gov.br/sesu/arquivos/pdf/ed_basdire.pdf . Acesso em: 06 de maio de 2021.

CERQUEIRA, Jonir Bechara; FERREIRA, Elise de Melo Borba. Recursos Didáticos na Educação Especial. Revista Benjamin Constant, Rio de Janeiro, nº5., p.15-20. 1996.

DENZIN, Norman Kent; LINCOLN, Yvonna Sessions. O planejamento da pesquisa qualitativa. 2006. Porto Alegre: Penso.

DOURADO, Luiz Fernandez. Diretrizes Curriculares Nacionais para a formação inicial e continuada dos professionais do Magistério da Educação Básica: Concepções e Desafios. Educação \& Sociedade, Campinas, v. 36, nº 131, p. 299-324, abr.-jun., 2015.

GANZELA, Marcelo. O leitor como protagonista: reflexões sobre metodologias ativas nas aulas de literatura. In: BACICH, Lilian; MORAN, José. (orgs). Metodologias ativas para uma educação inovadora. Porto Alegre: Penso, 2018.

GIL, Antonio Carlos. Como elaborar projetos de pesquisa. 4. ed. São Paulo: Atlas, 2008.

IMBERNÓN, Francisco. Formação docente e profissional: formar-se para a mudança e a incerteza. 7. Ed. São Paulo: Cortez, 2010.

KRASILCHIK, Myriam. Prática de ensino de biologia. 4ª ed., São Paulo: Editora Edusp, 2008.

LEAL, Edvalda Araújo; MIRANDA, Gilberto José; NOVA, Silvia Pereira Castro Casa. Revolucionando a sala de aula: como envolver o estudante aplicando as técnicas de metodologias ativas de aprendizagem. 1.Ed.- [3. Reimpre.] - São Paulo: Atlas, 2019.

LÉVY, Pierre. Cibercultura. São Paulo: Editora 34, 1999.

LIBÂNEO, José Carlos. Didática. São Paulo: Editora Cortez, 1994.

LIBÂNEO, José Carlos. Educação escolar: políticas, estrutura e organização. 5.ed. São Paulo: Cortez, 2007.

MARTINS, Maria Cecília. Integração das mídias e práticas pedagógicas. In: VALENTE, José Armando; ALMEIDA, Maria Elizabeth Bisnconcini de (Org.). Formação de educadores à distância e integração de mídias. São Paulo: Avercamp, 2007. 
MORAN, José Manuel; MASETTO, Marcos T.; BEHRENS, Marilda Aparecida. Interferência dos meios de comunicação no nosso conhecimento. INTERCOM, Revista Brasileira de Comunicação, São Paulo, v.17, n.2, jul.-dez. 1994.

MORAN, José Manuel et al. Novas tecnologias e mediação pedagógica. 6. ed. Campinas: Papirus, 2000.

MORAN, José Manuel; MASETTO, Marcos Tarciso.; BEHRENS, Marilda Aparecida. (Ed.). Novas tecnologias e mediações pedagógicas. 13. ed. São Paulo: Papirus, 2007.

NAGUMO, Estevon. O uso do aparelho celular dos estudantes na escola. Dissertação (Mestrado em Educação). Universidade de Brasília. Brasília-DF, 2014.

PIMENTA, Selma Garrido. Formação de professores: identidade e saberes da docência. In: PIMENTA, Selma. Garrido.et al. (Org.). Saberes pedagógicos e atividade docente. 4. ed. São Paulo: Cortez, 2005. p. 15-34.

SAMPAIO, Marisa Narcizo, LEITE, Lígia Silva. Alfabetização tecnológica do professor. Petrópolis, RJ: Vozes, 1999.

STAINBACK, Susan; STAIMBACK, William. Inclusão: um guia para educadores. Porto Alegre: Artmed, 1999.

STRAUB, Sandra Luzia Wrobel. Estratégias, desafios e perspectivas do uso da Informática na educação- realidade na escola pública. Cáceres: Ed. UNEMAT, 2009.

TARDIF, Maurice. Saberes docentes e formação profissional. 17.ed. Petrópolis, RJ: Vozes, 2014.

UNESCO. Diretrizes de Políticas para a Aprendizagem Móvel. Brasília, 2014.

VALENTE, José Armando. Diferentes usos do computador na Educação. In: VALENTE, José Armando. Computadores e Conhecimento: repensando a educação, p. 1-23, 1999.

VEIGA, Ilma Passos Alencastro. Formação de professores: Políticas e Debates. SÃO PAULO: PAIPRUS, 2008.

XAVIER, Antonio Carlos dos Santos. O Hipertexto na Sociedade da Informação: a constituição do modo de enunciação digital. Tese de doutorado Unicamp, 2005.

\section{Agradecimentos}

Agradeço primeiramente a Deus, pela permissão e realização desta pesquisa.

Agradeço de modo especial à professora $\operatorname{Dr}^{\mathrm{a}}$ Edione Teixeira de Carvalho, pela paciência com que conduziu o processo de iniciar esta discípula nos caminhos da pesquisa.

Agradeço à gestão e a todos os professores da Escola Estadual Conquista D'Oeste, pela colaboração com a pesquisa. 